\title{
Labor Force Structure, Potential Output, and Productivity
}

ECONOMISTS HAVE ATTEMPTED TO ESTIMATE potential gross national product for over a decade now. Potential GNP measures the output the economy would produce if it were operating at some fixed, fairly low level of unemployment, usually defined by an aggregate unemployment rate of about 4 percent. The difference between potential and actual GNP at any point in time is known as the GNP gap. In 1962, Arthur Okun published an analysis that has been the benchmark for official measures of potential GNP ever since, and in the process enunciated what came to be known as Okun's law, which relates the unemployment rate to the percentage GNP gap. ${ }^{1}$ Potential GNP and Okun's law became two of the handiest tools of analysis and presentation for economic stabilization problems. Particularly during the first half of the 1960s, when GNP was running below potential and policy was devoted to closing the gap, no sophisticated analysis of the economy failed to identify the loss in real output that was associated with an economy falling short of full employment.

The careful estimation of the full employment surplus in the federal budget has been an important by-product of the estimation of potential

* I want to thank Nancy Hwang and Herbert F. Lowrey, Jr., who did all of the computations in this paper.

1. Arthur M. Okun, "Potential GNP: Its Measurement and Significance," in American Statistical Association, Proceedings of the Business and Economic Statistics Section (1962), pp. 98-104. 
GNP. ${ }^{2}$ By estimating the revenues and expenditures that would be generated by the economy operating at its potential level, and comparing these with actual revenues and expenditures, one can determine with a useful degree of precision that part of a budget surplus or deficit attributable to cyclical deviations in the economy around potential. Medium-term projections of the economy have also come to depend on projections of potential GNP. The last two reports of the Council of Economic Advisers have used the concept in this way, projecting the total GNP that would be available in future years and the various end uses to which it could be put under alternative economic policies.

The attempts over the last decade to quantify potential output have focused attention on two important matters: the implications, in terms of lost output, incomes, and revenues, of operating the economy below its potential level; and the changes that could be expected in the growth rate of the economy's potential as a result of changes in the factors that underlie it.

Corresponding to the two kinds of analytic insights just mentioned are two basic ways of approaching the measurement of potential output. One can analyze the relation between the GNP gap and the unemployment rate at any moment of time. This approach involves estimating the differences in employment, average hours worked by each employee, and average productivity of each employee that would accompany the difference between the actual and target unemployment rate. Or one can start from a benchmark period for which potential output is known, and estimate the changes in potential output for other years from information about the sources of these changes. Although some fairly elaborate models of economic growth have been used for this purpose, this procedure, at its simplest, involves estimating the changes in the labor force and hence employment, in average hours worked by the employed, and in output per manhour that have prevailed or can be expected to prevail along the potential path.

In his original article, Okun wedded these approaches to measuring potential. He came out with estimates, first, of how potential output grew through time, and, second, of how the gap between potential and actual GNP was related to the unemployment rate at a particular time-Okun's law. According to Okun's law, the percentage GNP gap is a little over three times the excess of the unemployment rate over 4 percent, where

2. See, for example, Arthur M. Okun and Nancy H. Teeters, "The Full Employment Surplus Revisited,” Brookings Papers on Economic Activity (1:1970), pp. 77-110. 
potential is defined as the output the economy would produce with 4 percent unemployment.

In describing the other approach to the problem-measuring the ingredients of growth in the economy's potential output year by year-Okun found a trend growth rate of 3.5 percent a year during the years covered by his study (1954-62) and, in simplest form, decomposed this growth into a 1.2 percent and a 2.3 percent annual rate of growth in the labor force and in output per man employed, respectively, estimates that took account of a gradual decline in average hours worked per man during the period.

As economic expansion narrowed the GNP gap that had existed at the time Okun made these estimates, both these methods of estimating potential GNP stood up very well. By the middle of the decade, the gap had been closed and actual GNP corresponded to estimated potential. But since 1965, some unexpected things have happened to the determinants of potential GNP.

After growing at nearly the predicted potential rate of 1.2 percent during the previous decade, the labor force grew at an average annual rate of almost 2.4 percent between 1965 and 1970. With the simplified formula that allows for a 2.3 percent trend growth rate in output per man, an expansion this rapid in the potential labor force would indicate a 4.7 percent annual growth in potential GNP over the interval. This rate is much faster than anyone had projected and much faster than that which actually developed, despite falling unemployment rates over most of the period.

However, during these same years, the unexpected surge in labor force growth was accompanied by an equally unexpected dip in average hours worked per employee, and disappointing growth in actual labor productivity. In Table 1, the actual changes in the labor force, average hours of

\section{Table 1. Annual Growth Rates of Labor Force, Weekly Hours, and Output per Manhour, 1948-70}

Percentage

\begin{tabular}{cccc}
\hline Period & $\begin{array}{l}\text { Labor } \\
\text { force }\end{array}$ & $\begin{array}{l}\text { Average } \\
\text { weekly } \\
\text { hours }\end{array}$ & $\begin{array}{c}\text { Output } \\
\text { per } \\
\text { manhour }\end{array}$ \\
\hline $1948-55$ & 1.49 & -0.47 & 3.45 \\
$1955-65$ & 1.16 & -0.39 & 2.75 \\
$1965-70$ & 2.35 & -0.78 & 1.63 \\
\hline
\end{tabular}

Sources: For labor force data, see appendix; other series are calculated by the author from data supplied by Edward F. Denison from a draft of his forthcoming study. See note 6, p. 538, for amplification. 
work, and productivity over this period are compared with their changes in earlier years. The surprises in hours of work and productivity affected output growth in the opposite direction from the surge in the labor force. As a result, until 1969, Okun's law kept working well in relation to the official estimates of potential.

Official estimates, reflected in the Economic Report of the President and in the Census Bureau publication, Business Conditions Digest, accept the methodology of adding trend productivity growth to the growth of the potential manhours of labor input in the economy in order to measure the growth of potential output. But the official estimates of these components of potential output growth are periodically adjusted to reflect developments in actual output and unemployment. They indicate that potential output grew at an average annual rate of about 4 percent from 1965 to 1970. This downward adjustment from the naïve 4.7 percent growth projection is in the right direction, but the justification for it is not clear. Which of the changes shown in Table 1 are likely to represent new trends in the components of potential output growth, which are likely to prove transitory, and how do they add up to a quantitative estimate of current potential GNP?

The performance of productivity over this interval is of particular interest in itself. Changes in the productivity trend have important implications for the level of profits in the economy ${ }^{3}$ and for the distribution of income more generally. They are significant for understanding inflation since the productivity trend determines the translation of hourly wage costs into standard wage costs per unit of output, which constitute the prime determinant of price movements. ${ }^{4}$

\section{Elements of GNP Growth}

\section{WEIGHTED LABOR FORCE VARIABLES}

In a recent paper I discussed the significance of the changing age-sex composition of the pool of unemployed workers for the question of inflation. ${ }^{5}$ I noted that large and persistent differences exist in the effective

3. Arthur M. Okun and George L. Perry, "Notes and Numbers on the Profits Squeeze," Brookings Papers on Economic Activity (3:1970), pp. 466-72.

4. Robert J. Gordon, "Inflation in Recession and Recovery," Brookings Papers on Economic Activity (1:1971), pp. 105-58.

5. George L. Perry, "Changing Labor Markets and Inflation," Brookings Papers on Economic Activity (3:1970), pp. 411-41. 
labor supply offered by individuals in the several age-sex groups. In order to take account of these differences, the average wage and average number of hours worked per week by individuals in the various groups were used to weight the number of individuals in each group. This led to the concept of a weighted unemployment rate, defined as the ratio of weighted total unemployment to the weighted total labor force. The same weighting adjustments are even more directly relevant for measuring the real labor input associated with a given employment total. So it is natural to conduct an analysis of productivity and potential output in these terms.

The effect of the changing composition of employment has always been implicitly accounted for in past studies of potential output growth. Changes in the relative composition of employment that change average labor productivity or average hours worked per man become one element determining the average trend in these sources of growth. But if the compositional change is not proceeding at a steady rate, it becomes important to take explicit account of its effect in order to isolate other changes that may be taking place. In order to do this, I have used relative wages and hours of work to weight the various labor force groups. Because employment and average hours are generally treated separately in analyzing potential output growth, it seemed most natural to weight employment by the relative wages of the age-sex groups and to use differences in average hours among groups to help explain the observed movements in economywide average hours. Weighted employment thus refers to the sum of wage-weighted employment for each age-sex group, with the wage weights corresponding to the relative wages earned by the average worker in each age-sex group. These wage weights are proxies for the relative productivities of workers. In the weighted employment total, an employee whose productivity (as measured by his wage) is only half the average productivity of all workers gets only half weight.

Since the composition of the work force has been shifting continually toward relatively more women and young workers, individuals who have relatively low wage weights, the growth rate of weighted employment is lower than that of officially measured employment throughout the postwar period. But while the difference between the growth rate of the two measures averaged about 0.2 percentage point until 1965, it became 0.5 percentage point during the 1965-70 period. This change makes it especially important to use the weighted employment variable in analyzing the trend of productivity and potential output in recent years.

In order to examine potential growth and some of its characteristics 
more carefully, I have used the weighted labor force concepts to conduct a new analysis covering the whole postwar period. This involves estimating the trend growth of labor force participation rates, average hours per worker, and productivity along the potential path, and their departure from trend values associated with operating at output levels other than potential GNP. Taking explicit account of labor force composition turns out to provide new information on these estimates of potential and assists understanding of the recent behavior of productivity.

\section{PARTICIPATION RATES}

For some groups in the population, notably women and young workers, the fraction of the population that is in the labor force has varied substantially over the postwar period. These labor force participation rates vary cyclically, with a larger fraction of the population in the labor force when unemployment is low than when it is high. They also vary through time for reasons that are independent of the unemployment rate. Over most of the postwar period, participation rates in these groups have risen. While both the cyclical sensitivity and the rising trend of participation rates stand out clearly in the data, the precise forces governing participation rates are complex. They can be approximated only crudely by statistical relations that try to explain participation rates in terms of unemployment rates and a time trend. However, it is impossible to take explicit account of all the things that should help explain participation rates. And estimates of the potential labor force are needed. ${ }^{6}$

As a necessary compromise, I have let actual labor force growth tell most of the story. The first step was to estimate participation rate equations of the following form:

$$
\left(\frac{L_{i}}{P_{i}}\right)_{t}=A+a_{i}\left(1-u_{t}^{*}\right)+b_{i} \log T_{t}
$$

6. The labor force and employment data and the data on average hours of work that are used in this paper are based on data supplied by Edward F. Denison from a draft of a forthcoming study. They are derived primarily from the establishment-based data of the Office of Business Economics, which are published in July issues of the Survey of Current Business, with additions made for workers not covered by the establishment data in order to make the labor input total comparable with the output total represented by real GNP. The appendix describes how I matched these data to the official labor force series adjusted for definition and census benchmark changes in order to allocate the total among the age-sex groups in the population. 
where

$$
\begin{aligned}
L= & \text { labor force } \\
P= & \text { population } \\
i= & \text { subscript designating age-sex groups } \\
t= & \text { dating subscript } \\
A= & \text { a constant } \\
u^{*}= & \text { weighted unemployment rate as defined above, with } 1-u^{*}, \text { the } \\
& \text { weighted unemployment rate, taken as a measure of labor mar- } \\
& \text { ket tightness }
\end{aligned}
$$

$\log T=$ a time-trend term in which $T$ equals 100 in the first quarter of 1948 and rises by 4 each year.

A separate equation was estimated for each age-sex group from annual data fitted to 1948-69. The estimates are given in the appendix. ${ }^{7}$

Generally, equations of this form are used to estimate potential participation rates by setting the employment rate at its potential value and solving for the participation rate in each year. ${ }^{8}$ This simply allows the estimated time trend to determine the path of potential participation rates. Rather than doing this, I have used the employment rate coefficient, $a_{i}$, to adjust the actual participation rate each year to an estimated potential level for that year. The difference between the actual and potential weighted employment rate is multiplied by $a_{i}$ to get the estimated marginal change in participation rates that would have come from being at the potential unemployment rate. Thus the time trend in equation (1) serves simply as the best available variable to use in arriving at an accurate estimate of the effect of unemployment on participation rates. Since factors affecting the trend of the potential labor force should be expected to affect the actual labor force as well, this procedure should yield more sensible estimates, particularly for the crucial period of the late 1960s. In that period, unemployment was near its potential level, thus minimizing the error from the marginal adjustment that is made.

7. Equations using lagged as well as current employment rates were tried, but the lagged terms were insignificant. I also tried the employment rate squared, both adding it to equation (1) and using it by itself, to see if the effect was nonlinear, but it was not. Equations using the conventional unemployment rate in place of $u^{*}$ gave slightly inferior fits.

8. N. J. Simler and Alfred Tella, "Labor Reserves and the Phillips Curve," Review of Economics and Statistics, Vol. 50 (February 1968), pp. 32-49; and Gordon, "Inflation in Recession and Recovery," especially Appendix B, pp. 149-53. 
This way of estimating makes a big difference in recent years when actual participation rates have climbed much faster than any equation fitted to earlier periods would have predicted. Had predictions been made directly from the equation, the potential labor force would have been estimated well below the actual labor force, even after adjustment of the actual labor force for unemployment experience in the period. Perhaps a one-year surge in participation rates could have been regarded as aberrant and as irrelevant to an estimate of the trend of potential. But after five years of such experience, one must accept the verdict of the actual data. The fact that lagged employment rates and nonlinear forms of the employment rate were not useful variables in the equation further strengthens the presumption that a change in the trend of participation rates occurred in this period.

After potential participation rates for each year for each age-sex group were estimated in the manner just described, the potential labor force was projected separately for each group by multiplying its potential participation rate by its population in each year. The total potential labor force series is given in the appendix.

The effect of unemployment on the overall labor force participation rate varies through time with the changing composition of the work force. For recent years, the estimates indicate that a drop of one percentage point in the official unemployment rate would induce an increase of 500,000 in the labor force. Thus, taking account of this enlarged labor force, an employment increase of 1,340,000 workers, or 1.6 percent, would be needed to reduce the unemployment rate 1 percentage point.

\section{POTENTIAL WEIGHTED EMPLOYMENT}

Potential employment was calculated using the estimates of each group's potential labor force together with an estimate of what each group's unemployment rate would be along the potential path each year. These unemployment rate estimates were made by adjusting each year's actual unemployment rate for each group as described in the appendix. Just as in calculating actual weighted employment, potential employment in each group was multiplied by the relative wage for the group, and these estimates were added over all age-sex groups to arrive at potential weighted employment for the whole economy. 


\section{AVERAGE HOURS}

Over the postwar period, the average hours worked per year per employee show clear cyclical fluctuations as well as a persistent downward trend. The cyclical fluctuations demonstrate mainly that employers vary average hours as well as employment in response to changes in their own demand for labor. Higher unemployment rates mean less overtime and an increase in short workweeks of employment. To a smaller extent, the cyclical fluctuation in average hours may reflect some relative shift in employment away from manufacturing industries, where average weekly hours are high, and toward less cyclically sensitive industries, such as retail sales and services, where the standard workweek is shorter. The downward trend in average hours that is apparent once cyclical fluctuations are accounted for has not proceeded at the same rate throughout the postwar period. Through the mid-1950s, the downtrend was relatively fast as manufacturing industries moved to a standard forty-hour week. After that time, there was little further drift in the standard manufacturing workweek, and the economy-wide downtrend in average hours slowed. Then, surprisingly, average hours declined sharply again in the 1965-68 period.

Because there are persistent differences in the relative number of average hours worked by different age-sex groups in the labor force, the changing mix of employment contributes to the trend in economy-wide average hours of work. In order to isolate underlying trends in average hours from the effects of the changing employment mix, I eliminated the annual change in hours that was due purely to changes in the relative mix in employment. The resulting series was then explained by its statistical relationship to the weighted unemployment rate and time trends. The best-fitting equation for the postwar period was

$$
\begin{gathered}
A H_{t}=43.45-0.195 u_{t}^{*}-0.209 T_{1_{t}}+0.073 T_{2_{t}}-0.135 T_{3_{t}}, \\
(-6.68) \quad(-11.17) \quad(2.92) \quad(-2.81) \\
\bar{R}^{2}=0.986 ; \text { standard error }=0.125 ; \text { Durbin-Watson }=1.50 . \\
\text { The numbers in parentheses are } t \text {-statistics. }
\end{gathered}
$$

where $A H$ is average hours worked per week, $u^{*}$ is the weighted unemployment rate, and the $T \mathrm{~s}$ are separate time-trend variables. In the equation, $T_{1}$ and $T_{2}$ begin in 1947 and 1955, respectively, and continue throughout the period; $T_{3}$ runs from 1966 to 1968 and remains at its 1968 level thereafter. These time-trend variables explain the data better than any alternative I tried. 
The last trend variable, $T_{3}$, is clearly contrived to fit the data, and I have no independent reason to justify it. That it was needed even with data cleansed of employment mix effects is evidence that the 1965-68 decline in average hours is based on much more than the sharp rise in the employment of workers from age-sex categories with short workweeks. I conducted some other tests that convinced me that the recent decline in hours should be treated as a permanent change in the level of the trend. In particular, it did not appear that employers were reacting to the very tight labor markets of these years by hiring more employees than they normally would have in case they would be needed later, compensating by reducing average hours of work more than they normally would. If this had been the case, it should have shown up in the statistics on involuntary part-time employment. The fraction of workers on part time for economic reasons is historically closely related to the unemployment rate. Regressions showed that, during these years, the historical relationship continues to explain this category of part-time employment with no unusual errors. Equation (2) should already account for normal effects of the changing composition of employment. To check further, I ran regressions on voluntary part-time employment as a fraction of total employment for each age-sex group. This fraction is inversely related to the unemployment rate, indicating that a greater-than-average proportion of marginal workers choose to work part time. Once that source of variation is accounted for, there remains a clear increase during the last half of the 1960s in the proportion of employment that is voluntarily part time in each age-sex group taken separately. The composition change adds to this decline.

The trend in average hours indicated by equation (2) was adjusted by adding back the changes due to mix effect that would occur along the potential path. Because the separate time trends give abrupt changes in this path of potential average manhours, the final series was smoothed by forming centered three-year moving averages for use in estimating potential GNP.

According to these estimates, a fall of 1 percentage point in the weighted unemployment rate causes a 0.20 hour rise in average weekly hours worked per employee; or, equivalently, there is a 0.18 hour rise for a fall of 1 percentage point in the official unemployment rate. The time trends in equation (2) indicate that, with a constant weighted unemployment rate, average weekly hours fall by 0.21 hour per year from 1948 to 1955, by 
0.14 hour per year from 1955 to 1965 , by 0.27 hour per year from 1965 to 1968 , and by 0.14 hour per year thereafter. ${ }^{9}$

\section{OUTPUT GROWTH PATHS}

The estimates of potential weighted unemployment and potential average hours worked per employee just described provide the basis for calculating the economy's potential labor input. It will be measured by weighted potential manhours, defined as the product of weighted employment and average hours, both calculated along the potential path. The next step is to use this labor input measure to analyze the behavior of productivity in the economy, and from there to analyze potential output.

An awkward problem of terminology now arises. I want to retain the accepted normative definition of potential output as the output that would be produced with the economy operating at around a 4 percent official unemployment rate. Thus the modifier "potential" will continue to refer to magnitudes defined along a path corresponding to a constant official unemployment rate. But analytically, it becomes more natural for some purposes to work with the growth path defined by a constant weighted unemployment rate. So I shall use the modifier "trend" to refer to magnitudes defined along a growth path corresponding to a constant weighted unemployment rate. Both the trend and potential paths are defined to pass through the actual real GNP level in the third quarter of 1955, a convention that defines the unemployment rate along the potential path to be 3.87 percent with the labor force data used here and the weighted unemployment rate along the trend path to be 3.37 percent. ${ }^{10}$

Because of gradual changes in the age-sex composition of total unemployment, the official unemployment rate has been rising gradually along the employment path defined by a constant weighted unemployment rate.

9. The time trends in equation (2) decline by a constant amount each year rather than a constant percentage. Thus the percentage decline they project would gradually increase, but I would have no confidence in projecting so far ahead with this equation that this effect became important.

10. These unemployment rates are based on data that include the armed forces in employment and the labor force and that are adjusted for census benchmark revisions and definition changes, as discussed in the appendix. At present, the official unemployment rate corresponding to the potential path is 4.05 percent. The values of weighted employment and average hours along the trend path are estimated in a manner exactly analogous to the estimates made along the potential path that are described above. 
Thus potential output and trend output differ by noticeable amounts. But it makes little difference whether the analytics described here are conducted along the trend path and then adjusted to potential, as I do, or conducted along the potential path in the first place.

\section{A Model of Productivity and Output}

The procedure for estimating trend GNP starts by wedding propositions about the behavior of labor productivity, and applies them to wageweighted employment rather than to employment as conventionally measured. These propositions correspond to the two ways of viewing the concept of trend GNP: as a fairly smooth growth path passing through years when GNP is known to have been at its trend level (a growth view); and as a predictable relationship between the deviation of GNP from its trend and the weighted unemployment rate (a gap view). The simplest version of the model will be explained first and then some elaborations of it will be reported.

The proposition that, along the trend output path, weighted labor productivity grows at a constant rate is expressed by the formula

$$
\left(\frac{\bar{Q}}{\bar{H}}\right)_{t}=B e^{r T} t
$$

Here $\bar{Q}$ and $\bar{H}$ are the hypothetical levels of output (real GNP) and labor input (weighted trend manhours) along the growth trend of the economy defined by a constant (low) weighted unemployment rate. The trend of weighted labor productivity grows at the rate $r$ each year; $T$ is a time trend; and $B$ is a constant.

The proposition that, in any given year, weighted labor productivity is higher the higher the level of labor input can be expressed directly by a formula such as

$$
\left(\frac{\bar{Q}}{Q}\right)_{t}=\left(\frac{\bar{H}}{H}\right)_{t}^{b}
$$

where $b$ is expected to be greater than 1 . In this equation, $\bar{Q}$ and $\bar{H}$ are again the hypothetical levels of output and labor input at trend, while $Q$ and $H$ are the observed levels of output and labor input at that same point 
in time. This equation is equivalent to a relation expressed directly in terms of weighted labor productivity, $P$, of the following form:

$$
\left(\frac{\bar{P}}{P}\right)_{t}=\left(\frac{\bar{H}}{H}\right)_{t}^{b-1} \text {. }
$$

The combining of the growth and gap equations, (3) and (4), results in an equation from which to estimate the growth rate, $r$, and the proportionality factor, $b$, using only the trend labor input estimated earlier and actual, observable data on output and labor input:

$$
Q_{t}=B e^{r T} t \bar{H}_{t}^{1-b} H_{t}^{b} .
$$

For estimation purposes, this equation is expressed in logarithmic form:

$$
\log \left(\frac{Q}{\bar{H}}\right)_{t}=\log B+r T_{t}+b \log \left(\frac{H}{\bar{H}}\right)_{t}
$$

\section{CHANGES IN TREND PRODUCTIVITY}

Although the weighted productivity trend may grow smoothly, the assumption that its growth rate never changed throughout the postwar period, as implied by equation (3), may be too restrictive. In particular, aggregate production functions for the economy that explicitly measure the input of capital as well as of labor result in estimates of potential labor productivity that depend on the size of the capital stock at any time. ${ }^{11}$ Such models imply that, other factors being equal, the growth rate of labor productivity will be positively related to the growth rate of the capital stock with which labor works. In practice, attempts to measure such aggregate production functions have not led to estimates of labor productivity that show sharp changes in its growth rate over the postwar period. Changes in the capital-labor ratio, the infusion of new technology, and improvements in the average education of the work force-the major influences on labor productivity-come about only gradually.

Still, the assumption of a completely unchanged rate of productivity growth along the trend path may be too restrictive. Equation (6) was

11. Lester C. Thurow and L. D. Taylor, "The Interaction between the Actual and the Potential Rates of Growth," Review of Economics and Statistics, Vol. 48 (November 1966), pp. 351-60; and Robert M. Solow, "Technical Progress, Capital Formation, and Economic Growth," in American Economic Association, Papers and Proceedings of the Seventy-fourth Annual Meeting, 1961 (American Economic Review, Vol. 52, May 1962), pp. 76-86. 
estimated separately for various subperiods of the postwar years in order to see if noticeable differences in the estimated productivity trend could be observed. Differences did arise but, invariably, changes in the estimates of $r$, the productivity trend, went along with changes in the estimate of $b$, the cyclical productivity term. This was particularly noticeable when subperiods were broken at extremes of cyclical peaks or troughs such as 1953, indicating that the statistical estimates were confusing the two sources of change in actual labor productivity. In order to minimize this problem, the equations were constrained to keep the cyclical response of productivity measured by $b$ unchanged throughout the period, while permitting the trend of productivity, $r$, to vary by introducing additional time trends. The new estimating equation embodying these assumptions is

$$
\log \left(\frac{Q}{\bar{H}}\right)_{t}=\log B+r_{1} T_{1_{t}}+r_{2} T_{2_{t}}+r_{3} T_{3_{t}}+b \log \left(\frac{H}{\bar{H}}\right)_{t} .
$$

The several productivity terms, $r_{1}, r_{2}$, and $r_{3}$, are additive for all times when their corresponding time indexes are nonzero. To examine the possibility that the productivity trend changed at various times during the postwar period, the periods for starting the time indexes were varied. This method of scanning the data for possible interruptions in the productivity trend invites the discovery of breaks that may be spurious. The estimates obtained must be viewed with this in mind. On the other hand, the failure to achieve improvement in statistical fit with the additional time trends would be fairly strong evidence that the trend growth of productivity did not vary noticeably over the period.

\section{VARIATION IN GAP RESPONSE}

Equation (4a) implies that, at a given time, weighted labor productivity will be greater the higher the level of labor input. This tendency has been widely observed. But it is less clear that the productivity improvement should continue at the same rate as employment levels are pushed higher and higher. Should the productivity gain available from operating at 5 percent rather than 6 percent unemployment rates be expected to be the same as the improvement available in operating at 3 percent rather than 4 percent unemployment?

Many factors contribute to the increased productivity that is observed. Within a given industry, some employment is of an overhead nature, varying little if at all with variations in production. For the economy as a 
whole, industries whose production and employment are cyclically more sensitive experience, on the average, higher levels of labor productivity than most others; thus as these high-productivity industries increase their relative share of total employment, economy-wide average labor productivity increases. It is worth noting that the weighting of employees that has been used in this study could be expected partly to offset this last effect since the workers in industries with high labor productivity are relatively high-weight workers; this means that the effect identified as productivity change in studies with body-count measures of employment will be captured here, in part at least, as a change in weighted employment rather than in productivity. On the other hand, the overhead labor effect will probably appear more strongly in the present study, since technical and supervisory personnel, whose employment experiences cyclical variations below the average, tend to be high-weight individuals.

There are also forces working to reduce average labor productivity as employment levels rise, most notably the likelihood that the marginally unemployed at any time constitute a labor group with lower average skills than their employed counterparts. But most of this effect should disappear when labor input is measured by weighted employment.

It is beyond the scope of my purpose in this paper to try to sort out each of these effects. But I have tried to test whether their net effect changes as employment levels move nearer to potential and as they move above potential, as they did in recent years and during the Korean war period. In order to test this possibility, equation (4) was modified to allow the proportionality factor, $b$, to vary with the level of weighted unemployment, $u^{*}$, giving the following equation:

$$
\left(\frac{\bar{Q}}{Q}\right)_{t}=\left(\frac{\bar{H}}{H}\right)_{t}^{b_{1}+b_{2} u_{t}^{*}}
$$

In this form of the equation, the sum $b_{1}+b_{2} u^{*}$ gives the proportionality factor applicable at any time. If productivity increments become smaller the lower the unemployment rate, then $b_{1}$ and $b_{2}$ will both have positive signs. The estimating equation in logarithmic form, which now embodies both the possibility of variations in the long-run productivity trend and the adjustment just described, is

$$
\begin{aligned}
\log \left(\frac{Q}{\bar{H}}\right)_{t}=\log B+ & r_{1} T_{1_{t}}+r_{2} T_{2_{t}}+r_{3} T_{3_{t}}+b_{1} \log \left(\frac{H}{\bar{H}}\right)_{t} \\
& +b_{2}\left(u^{*} \log \frac{H}{\bar{H}}\right)_{t}
\end{aligned}
$$




\section{LAGS IN CYCLICAL RESPONSE}

The equations used thus far make no allowance for cyclical lags in the employment of labor. Reductions in the unemployment rate are known to lag behind a cyclical upturn. This situation reflects in part an increase in average hours of work that substitutes for an increase in employment. Also, there have been periods, such as 1956 and 1969, when productivity growth was interrupted following a substantial cyclical upswing. Some part of this interruption is due to the increasing employment of secondary workers at that stage of the cycle. This part of the effect would disappear with the labor input measure used here since it weights employment to eliminate productivity differences among workers and thus permits tests for those true lags in productivity that exist. Unfortunately, the use of annual data will reveal only substantial lags, and some genuine cyclical characteristics of the relation between output and labor input may be lost.

The change in the labor input gap was introduced into equation (4) to account for lag effects, ${ }^{12}$ yielding

$$
\left(\frac{\bar{Q}}{Q}\right)_{t}=\left(\frac{\bar{H}}{H}\right)_{t}^{b}\left[\left(\frac{\bar{H}}{H}\right)_{t}\left[\left(\frac{\bar{H}}{H}\right)_{t-1}\right]^{c} .\right.
$$

With allowance made again for changes in the productivity trend, this addition now leads to the estimating equation in logarithmic form

$$
\begin{aligned}
\log \left(\frac{Q}{\bar{H}}\right)_{t}= & \log B+r_{1} T_{1_{t}}+r_{2} T_{2_{t}}+r_{3} T_{3_{t}}+b \log \left(\frac{H}{\bar{H}}\right)_{t} \\
& +c\left[\log \left(\frac{H}{\bar{H}}\right)_{t}-\log \left(\frac{H}{\bar{H}}\right)_{t-1}\right] .
\end{aligned}
$$

\section{Statistical Estimates}

\section{ESTIMATES OF PRODUCTIVITY}

The estimates of the various forms of the model just discussed and shown in Table 2 permit a comparison of some alternative hypotheses about the behavior of productivity. One kind of comparison is among the three forms of equations. It permits selection, from among the gap-type specifications, of the form that best captures the relation between output

12. Lag effects could also be introduced by a change term such as $H_{t} / H_{t-1}$. This implies a slightly different response when the growth rate of $\bar{H}$ changes. Estimates using this alternative were slightly inferior to those with the form shown here. 


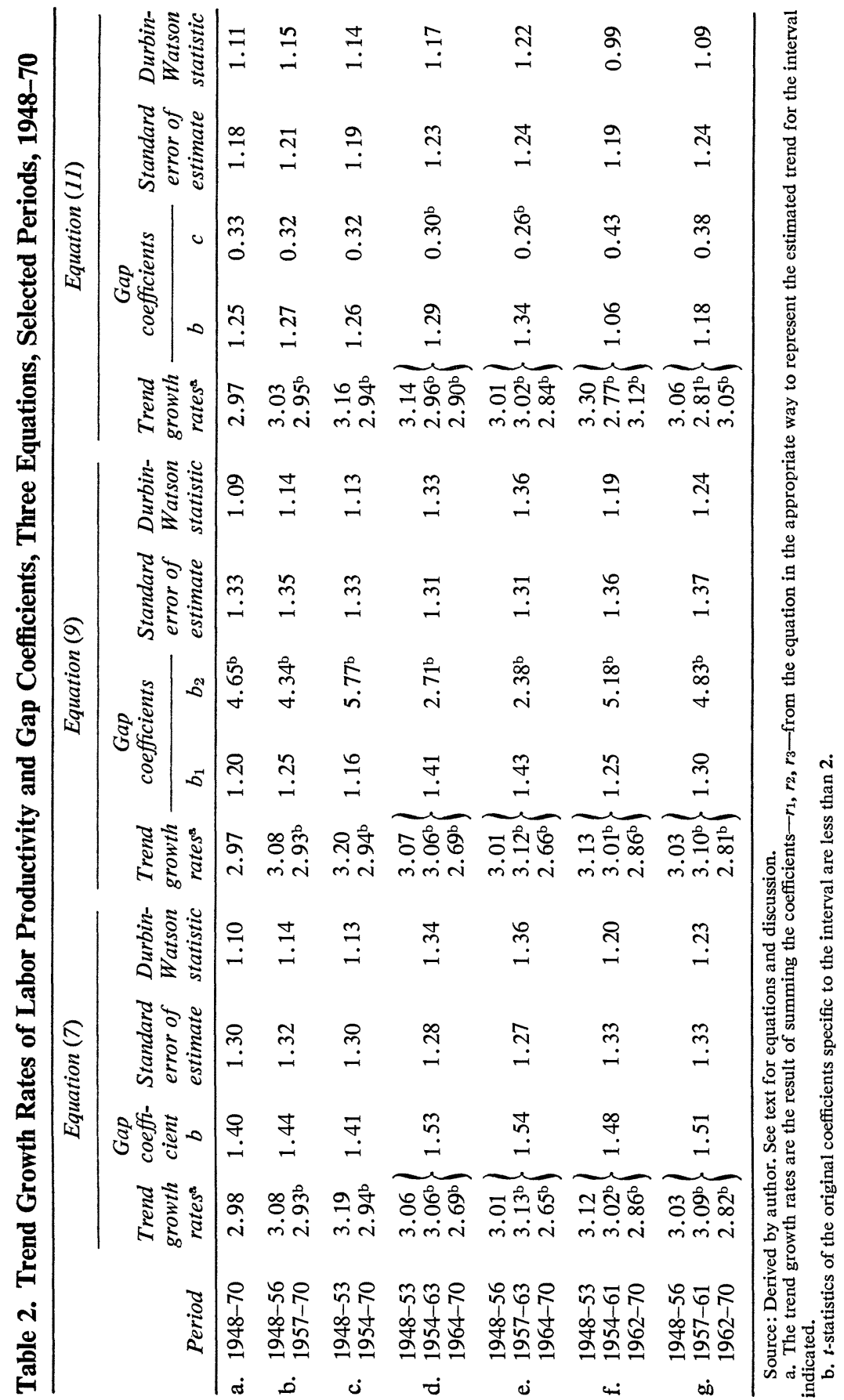


and labor input at a given point in time. A second kind of comparison is among the different time intervals chosen in fitting productivity trends. This comparison offers a test of whether productivity trends changed noticeably during the postwar period.

The results of changing productivity trends over various subintervals of the postwar period are shown by the letter designations in the stub of the table. Thus, for example, equation (9b) refers to the equation (9) form of the model with separate trends allowed for the two subperiods 1948-56 and 1957-70. The estimates for equation (9b) are shown in the middle bank of columns, labeled equation (9), and the second row, labeled (b).

Alternative equations. Equation (7) is the simplest form tested. Estimates using it are shown in the first bank of columns in Table 2. The estimates in row (a) correspond to equation (6), which is a special case of equation (7) in which the productivity trend is unchanged throughout the period.

Equation (9) allows the relation between the output gap and the labor input gap to vary with the weighted unemployment rate, which has the coefficient $b_{2}$ in the table. Estimates are shown in the second bank of columns in Table 2. The estimates of the coefficient $b_{2}$ have the right sign in the equation for every combination of subperiods, suggesting that there is some of the suspected effect: The productivity gains available from each increment of gap closing diminish as the gap itself gets smaller (or grows larger negatively). But while the expected sign persists, in no case is the coefficient estimate as much as twice as large as its standard error, and in most cases it is not larger than its standard error. In all cases, the standard error of estimate of the equation is worsened slightly rather than improved in the shift from the equation (7) to the equation (9) specification.

Equation (11), estimates for which are shown in the third bank of columns, allows the dynamics of employment change to affect the relation between output and employment. This amendment to the simple model yields better results. The positive coefficients estimated on the dynamic term are typically twice their standard error and the standard errors of estimate of all the equations are smaller than their counterparts in the estimates from equation (7).

The positive coefficients for the dynamic term predict the following pattern between labor input and output changes during a cyclical movement of the economy. Starting from a constant input gap, a surge of employment in one year will be accompanied by an especially large increase in output, 
improvement in productivity, and reduction in the output gap. If the input gap remains unchanged in the second year, with its growth just equal to its trend, it will be accompanied by a widening of the output gap and an increase in productivity slower than trend. If the input gap continues unchanged in the third year, output and productivity will grow at their trend rates and the output gap will remain unchanged. If input growth is especially slow in the fourth year and input gap widens, there will be an especially slow growth in output and productivity and an especially large increase in the output gap.

Alternative productivity trends. The most striking thing about comparisons of different rows in Table 2 is how favorably the estimates in row (a) compare with the others. These estimates constrain the productivity trend to take on a single value for the whole postwar period. Allowing the data to set different productivity trends for different subperiods, as is done in rows (b) through (g), usually increases the standard error of estimate of the equation. In the estimates in the third bank, which employ the dynamic labor input gap term, no alternative improves at all on the overall fit of the row (a) equation.

In the third bank, equation (11f) is of special interest because it gives the most strikingly different results from the other equations, and it fits the data virtually as well as equation (11a). It breaks the period after 1953, a peak year of very low unemployment, and again after 1961, a recession year. This produces a trend estimate of productivity growth in the 1954-61 period substantially slower than the trend either before or after that. It also leads to an estimate of virtually no pure gap effects on productivity, which is both doubtful a priori and inconsistent with all other estimates of this effect in the table. Finally equation (11f) makes a prediction error on productivity in 1970 twice as large as that of equation (11a).

Thus, the results reported in Table 2 lead me to accept the hypothesis that the weighted productivity trend was constant throughout the postwar period. There is no reason to reject the row (a) estimates in favor of any others.

\section{PRODUCTIVITY TRENDS}

Equation (11a) can be used to provide estimates of productivity and output trends. Two adjustments are necessary to produce estimates in conventional form. The first is simply to convert from the trend path, 
defined by a constant weighted unemployment rate, to the potential path, defined by a constant official unemployment rate. This conversion is discussed below in connection with estimating potential output and is not quantitatively important for estimates of productivity trends. The second adjustment is basic to the method used here. Equation (11a) says that, throughout the postwar period, weighted labor productivity grew at a constant rate of about 3 percent a year along the trend path. But this means that trend labor productivity as commonly measured-using unweighted manhours-varied as the relation between weighted and unweighted trend manhours varied. This proposition in turn implies a growth rate of trend productivity slower than 3 percent throughout the period, since the relative importance of low-weight employees grew. It also implies that the growth rate changed in various periods since the relative composition of employment did not change at the same rate throughout. Table 3 shows the effect of these shifts on conventionally measured productivity growth along the potential path. The annual rate of productivity advance slows from 2.9 percent in $1948-55$ to 2.7 percent in $1955-65$ and to 2.4 percent in 1965-70.

Table 3. Growth in Potential Output, by Source, 1948-70

Annual growth rates in percent

\begin{tabular}{lrrr}
\hline \multicolumn{1}{c}{ Output and sources of growth } & $1965-70$ & $1955-65$ & $1948-55$ \\
\hline Potential output & 4.16 & 3.53 & 3.90 \\
Sources & & & \\
$\quad$ Potential employment & 2.41 & 1.17 & 1.53 \\
Potential average hours, total & -0.67 & -0.36 & -0.53 \\
$\quad$ With constant employment mix & -0.53 & -0.29 & -0.48 \\
$\quad$ Effect of employment mix & -0.14 & -0.07 & -0.05 \\
Potential productivity, total & 2.39 & 2.71 & 2.87 \\
$\quad$ With constant employment mix & 2.93 & 2.97 & 2.99 \\
$\quad$ Effect of employment mix & -0.53 & -0.25 & -0.11 \\
Addendum & & & \\
Effect of employment mix & & & \\
$\quad$ on potential output & -0.67 & -0.32 & -0.16 \\
Trend output & 4.13 & 3.45 & 3.90 \\
\hline
\end{tabular}

Source: Calculated by author; see text. Figures are rounded and may not add to totals.

\section{Potential Output}

Equation (11a) is used to calculate potential output for the postwar years. The steps used in these calculations are as follows: 
1. The weighted unemployment rate that would prevail along the potential path was estimated for each year based on disaggregated unemployment totals by age-sex categories. (Along the potential path, the weighted unemployment rate declined noticeably from the mid-1950s to the late 1960s.)

2. The potential labor force by age-sex categories was then calculated using the unemployment coefficient in the participation rate equations to adjust the trend labor force. Weighted potential employment was calculated from this and combined with estimates of potential average hours from equation (2) to produce an estimate of potential labor input.

3. Potential output was calculated by fixing it equal to actual real GNP in the third quarter of 1955 and projecting the years before and after 1955 by using the growth rate of potential labor input each year in equation (11a).

\section{VARIATIONS IN POTENTIAL OUTPUT GROWTH}

Table 3 summarizes the growth rate of potential output and the sources of this potential growth for three subperiods of the postwar years. For the 1955-65 decade, it confirms the 3.5 percent potential growth rate that Okun had estimated. And it indicates that, in the earlier postwar period, potential had grown at nearly a 4 percent rate. But, of greatest interest, it shows why potential output growth accelerated by only 0.6 percentage point in the 1965-70 period compared with the previous decade, despite the strong evidence in Table 2 that trend-weighted productivity did not slow down in recent years and despite the jump of 1.2 percentage points in the growth rate of the potential labor force and employment.

During 1965-70, shifts in the composition of the work force reduced the average workweek by 0.07 percentage point a year more than in the previous decade. In addition, the downward trend in the length of the workweek independent of such relative employment shifts was 0.24 percentage point faster than during the previous decade. Thus 0.31 percentage point of employment growth was offset by a faster decline in the trend of average hours. At the same time, the changing composition of the work force reduced the growth of productivity-or the growth of effective employment as measured by productivity weighting - by 0.28 percentage point more than during the previous decade. Together these hours and productivity effects offset half of the 1.2 percentage point acceleration of potential employment. 
The yearly estimates of potential GNP in current prices are shown for the postwar period in Table 4, along with actual GNP and the gap between potential and actual. In Figure 1, the difference between potential GNP based on the model of this paper and the official estimates of potential GNP are shown for the period from 1952, the first year for which official estimates are available, up to the present. The discrepancy between the two estimates is largest at the start and end of the period, but is not particularly large at any point. However, the present estimates indicate a

Table 4. Potential and Actual GNP, 1948-70

Dollar amounts in billions of current dollars

\begin{tabular}{rrrrr}
\hline & & & \multicolumn{2}{c}{ Gap } \\
\cline { 4 - 5 } Year & Potential GNP & GNP & Percent & $\begin{array}{c}\text { Dollar } \\
\text { amount }\end{array}$ \\
\hline 1948 & $\$ 267.4$ & $\$ 257.6$ & $3.8 \%$ & $\$ 9.8$ \\
1949 & 276.6 & 256.5 & 7.9 & 20.2 \\
1950 & 292.0 & 284.8 & 2.5 & 7.2 \\
1951 & 324.6 & 328.4 & -1.2 & -3.8 \\
1952 & 343.8 & 345.5 & -0.5 & -1.7 \\
1953 & 360.5 & 364.6 & -1.1 & -4.1 \\
1954 & 379.0 & 364.8 & 3.9 & 14.2 \\
1955 & 399.0 & 398.0 & 0.2 & 1.0 \\
1956 & 426.3 & 419.2 & 1.7 & 7.1 \\
1957 & 458.1 & 441.1 & 3.8 & 17.0 \\
1958 & 485.1 & 447.3 & 8.5 & 37.8 \\
1959 & 510.3 & 483.7 & 5.5 & 26.6 \\
1960 & 536.7 & 503.7 & 6.5 & 33.0 \\
1961 & 562.7 & 520.1 & 8.2 & 42.6 \\
1962 & 589.2 & 560.3 & 5.1 & 28.9 \\
1963 & 617.8 & 590.5 & 4.6 & 27.3 \\
1964 & 651.0 & 632.4 & 2.9 & 18.6 \\
1965 & 688.9 & 684.9 & 0.6 & 4.0 \\
1966 & 736.8 & 749.9 & -1.7 & -13.1 \\
1967 & 792.3 & 793.9 & -0.2 & -1.6 \\
1968 & 857.5 & 864.2 & -0.8 & -6.7 \\
1969 & 937.2 & 929.1 & 0.9 & 8.1 \\
1970 & $1,030.8$ & 974.1 & 5.8 & 56.7 \\
\hline
\end{tabular}

Sources: Actual GNP-U.S. Office of Business Economics, The National Income and Product Accounts of the United States, 1929-1965: Statistical Tables (1966), Table 1.1, and Survey of Current Business, Vol. 51 (July 1971), and July issues for 1968, 1969, and 1970; potential GNP-derived by author from equation (11a) discussed in text. 
Figure 1. Difference between Present Estimates and Official Projections of Potential GNP, 1952-70

Difference (percent of potential)

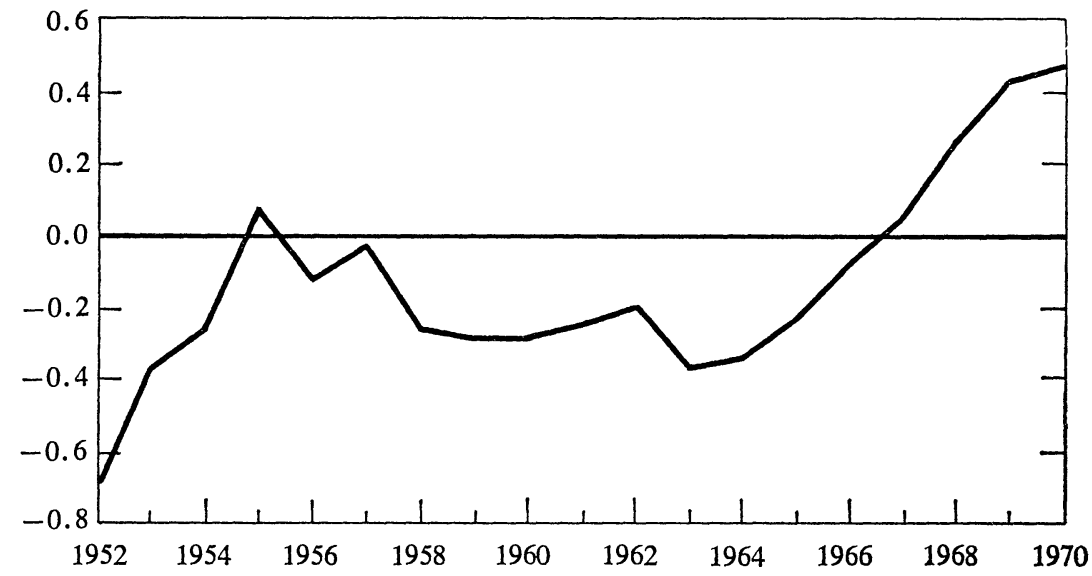

Sources: Derived from formula $\frac{\hat{Q}-\hat{Q}_{0}}{\hat{Q}}$, where $\hat{Q}=$ potential GNP estimated in this paper and $\hat{Q}_{o}=$ official estimate of potential GNP.

slightly smaller gap during the 1955-65 interval than the official estimates do. And they indicate a more rapid growth of potential between the early 1960s and the present.

\section{GNP Gaps and Okun's Law}

The GNP gap based on the potential output path can be decomposed into its employment, average hours, and productivity components using the same equations that were used to estimate potential GNP. At a point in time, a lower unemployment rate is associated with a larger labor force and employment level and longer average hours of work. These add up to a higher level of labor input, measured by weighted manhours. And this, in turn, is associated with a higher level of labor productivity. The higher levels of labor input and productivity measure the higher level of output that would be produced. Thus, specific estimates of each of these effects can be used to derive a relationship between the output gap and the unemployment rate, analogous to Okun's law. 
The increased employment associated with a reduction of one point in the unemployment rate can be estimated from the participation rate equations given in the appendix. Because disaggregated labor force data were used in the model, this relationship will vary slightly from year to year. For recent years, a one point difference in the unemployment rate implied about a 1.35 percent difference in weighted employment. From equation (2), a one point difference in the unemployment rate is associated with a 0.45 percent difference in average hours of work. When the hours and employment effects are added together, weighted labor input is greater by an estimated 1.8 percent for each 1 percentage point differential in the unemployment rate at a given point in time.

Equation (11) implies a relation between the productivity and labor input gaps of the following form:

$$
\left(\frac{\Delta P}{P}\right)_{t}=(b-1)\left(\frac{\Delta H}{H}\right)_{t}+c\left[\left(\frac{\Delta H}{H}\right)_{t}-\left(\frac{\Delta H}{H}\right)_{t-1}\right] .
$$

With $b$ estimated at 1.25 in equation (11a), the permanent elasticity of weighted productivity with respect to labor input is only 0.25 . Together with the 1.8 percent rise in labor input, this implies that only a 2.25 percent output gap is associated with one percentage point in the unemployment rate. Equation (12) also shows that a substantial additional gain in output and productivity would initially accompany a closing of the gap, since $c$ is equal to 0.33 , making the elasticity of productivity 0.58 in the first year the employment gap is narrowed. But this additional effect would be transitory. If equation (7a) is accepted in place of (11a), the permanent elasticity of weighted productivity to labor input is 0.40 , although the effect in the first year is smaller since there is no lag term. Together with the 1.8 percent difference in labor input, this implies that a 2.52 percent output gap accompanies each point in the unemployment rate. With the labor input effect estimated here, an elasticity of output to labor input of 1.78 would be needed to reach the 3.2 multiplier between the output gap and the unemployment rate that was estimated by Okun. None of the estimated values of $b$ in Table 2 approaches that magnitude.

\section{ALTERNATIVE SPECIFICATIONS}

The model of this paper basically asks what potential output level would accompany the potential unemployment rate. Okun really asked the 
opposite question: What output gain is needed to achieve a target, low unemployment rate? The Okun's law multiplier depends on which question is asked.

A model of output and productivity similar in form to equation (11) can be specified in terms of the second question. Keeping equation (3), which states that the productivity trend is constant, and changing equation (10) to

$$
\left(\frac{\bar{H}}{H}\right)_{t}=\left(\frac{\bar{Q}}{Q}\right)_{t}^{m}\left[\left(\frac{\bar{Q}}{Q}\right)_{t} /\left(\frac{\bar{Q}}{Q}\right)_{t-1}\right]^{n},
$$

where the expectation is that $0<m<1$, and $n<0$, yields an estimating equation of the form

$$
\begin{aligned}
\ln \left(\frac{\bar{H}}{H}\right)_{t}= & K+m r T_{t}+m \log \left(\frac{\bar{H}}{Q}\right)_{t} \\
& +n\left[\log \left(\frac{\bar{H}}{Q}\right)_{t}-\log \left(\frac{\bar{H}}{Q}\right)_{t-1}\right]
\end{aligned}
$$

(where $K$ is a constant), which implies a relation between the productivity and output gaps of the following form:

$$
\left(\frac{\Delta P}{P}\right)_{t}=(1-m)\left(\frac{\Delta Q}{Q}\right)_{t}-n\left[\left(\frac{\Delta Q}{Q}\right)_{t}-\left(\frac{\Delta Q}{Q}\right)_{t-1}\right] .
$$

The permanent elasticity of productivity with respect to labor input is given by $(1-m) / m$, with some additional transitory change in the same direction in the first year the gap changes, just as with equation (11).

Estimates from equation (14) fitted to the same period as equation (11a) show the following parameter values:

$$
\begin{aligned}
r & =2.98 \\
m & =0.68 \\
n & =-0.18 \\
1-m & =0.32 \\
(1-m) / m & =0.47 .
\end{aligned}
$$

The weighted productivity trend is still estimated to grow by 2.98 percent yearly, yielding the same potential GNP path estimated with equation (11a). The Okun's law multiplier is now 2.7, with weighted productivity rising by 0.86 percent along with the 1.8 percent rise in labor input for each drop of one point in the unemployment rate. 
Finally, the importance of the choice of question can be seen from estimates that retain the model of equation (11), but make output an independent variable. Doing this leaves the estimated productivity trend at 2.97 but raises the estimate of $b$ from 1.25 to 1.56 and lowers the estimate of $c$ from 0.33 to 0.18 . Thus, once again, the same potential GNP path is projected. But the Okun's law multiplier is now raised to 2.8 for permanent gap changes, while the additional transitory change in output and productivity is reduced. Even this estimate falls well short of Okun's original 3.2.

It is important to emphasize that the estimates of potential output shown in Table 3 are unchanged by any of these alternative specifications of the relation between employment and output. The potential path was calculated using the productivity trend, which is estimated to be just under 3.0 percent a year in all the variants discussed. Similarly, estimates of the size of the output gap, as well as the associated shortfall of actual employment, hours, and productivity from their values on the potential path, are the same for all variants since they are calculated as the difference between potential values, which are the same in all variants, and actual values in any year. However, in any year the error in explaining actual productivity will depend on the equation used, since each predicts somewhat different responses of productivity to deviations of the economy from the potential path.

\section{RECENT GNP GAPS AND PRODUCTIVITY}

In 1970, the estimated GNP gap, as shown in Table 4, was 5.8 percent of actual GNP, or about $\$ 57$ billion. An unusually large part of this estimated gap was associated with the fact that productivity was below its projected potential level. Average hours were 0.44 percent below potential; employment was 1.43 percent below potential; and productivity was 3.87 percent below potential. The employment shortfall represented 1.2 million jobs. Of these, 420,000 were the additional jobs associated with the larger labor force that would have been expected with the economy operating at its potential, and 750,000 represented a reduction in current unemployment.

The GNP gap was negative in 1966 and 1968, virtually zero in 1967, and 0.9 percent of GNP in 1969. The only other years in the postwar period with negative GNP gaps were 1951 through 1953.

On the basis of present evidence that real GNP is rising by a little less 
than 3.0 percent in 1971, the output gap will have grown to about 7.3 percent for the year, or to an estimated $\$ 77$ billion in current prices. This is about $\$ 5$ billion larger than the official estimates based on the same actual GNP. If output expands at a 5 percent annual rate in the fourth quarter of the year, the gap in that quarter will be about $\$ 78$ billion. The data needed to separate this output gap into the shortfall in labor input and the shortfall in productivity that exist in 1971 are not yet available. But the evidence that productivity growth in the private nonfarm sector has been rising rapidly indicates that low productivity will account for a smaller part of the total output gap in 1971 than it did in 1970.

Recent productivity. The poor performance of productivity over the 1965-70 period that has attracted so much attention can now be broken down into several components. During the previous decade productivity growth had averaged 2.75 percent per year. At that rate, it would have grown by 14.5 percent by 1970 ; but it grew only 8.4 percent, leaving a 5.3 percent shortfall from a naïve projection of past productivity trends. Of this shortfall, 1.5 percent is attributable to the acceleration that occurred in the employment of women and young workers relative to prime-age men. According to equation (11a), another 1.9 percent is accounted for by the predicted effect of slow growth of demand over this interval, and 1.9 percent is the unexpected shortfall in productivity (the error for 1970 from that equation). According to the estimates from equation (14), 2.7 percent is accounted for by the predicted effect of slow growth over the interval and 1.1 percent by the unexpected shortfall in productivity (the error for 1970 from that equation). This equation, which predicts a larger productivity difference between actual and potential output, correspondingly predicts lower productivity in 1970 and oence has a smaller error in that year when actual productivity was extraordinarily low. The substantial productivity gains noted for 1971 will make up at least some of the unexplained shortfall shown by both equations for 1970 .

\section{A Look Ahead}

\section{PROJECTED POTENTIAL OUTPUT}

With equation (11a), potential output growth can be projected over the decade of the 1970s. For this projection, the estimated time trends in the participation rate equations had to be relied on to project the future labor 
force by age-sex groups. The projections used as benchmarks the 1970 estimates of potential participation rates, which in turn were based on actual 1970 labor force data. No change was assumed to take place in the relative unemployment rates among age-sex groups at potential. The resulting employment projections by age-sex category were weighted by relative wages as before. Changes in potential average hours were estimated from equation (2) and adjusted for the effect of changing employment mix by age-sex categories. The age-sex adjustments were not substantial in the projection period.

On these assumptions, potential output grows at a rate of between 4.2 and 4.4 percent each year in the 1970s. For the decade, potential output growth averages 4.3 percent annually, an indisputable record for any decade in recent history. If the price deflator rises at an average annual rate of 2.5 percent over this period, potential GNP in current prices would reach $\$ 2$ trillion by the end of the seventies.

\section{UNEMPLOYMENT PREDICTIONS}

The projections of potential output growth in future years can be used to predict the unemployment rate that would accompany alternative rates of economic expansion. Since the aim is to predict employment for assumed output paths, equation (14) is used in this projection. For each output path considered, labor input is predicted from the equation and the labor input gap is calculated for each year. The official unemployment rate is then calculated from

$$
u_{t}=\frac{100}{1.8}\left(\frac{\hat{H}-H}{H}\right)_{t}+4.05
$$

(where $H$ is potential labor input), since 4.05 percent is the official unemployment rate at potential and 1.8 percent of labor input gap is associated with one point in the unemployment rate.

For 1972 and 1973, potential output is projected to grow at its fastest rate in the postwar period, averaging approximately 4.4 percent yearly. If real GNP grows at a 5 percent annual rate in the fourth quarter of 1971, calculations based on equations (15) and (16) predict a 6.0 percent official unemployment rate for the year, indicating they are tracking quite well. If real output continues to grow at a 5.0 percent rate in the following eight quarters, the unemployment rate is predicted to continue at 6.0 percent in 
1972 and to decline to only 5.8 percent in 1973 . This is a surprisingly slight improvement in unemployment in face of a rate of economic expansion that is substantially faster than the economy has experienced for some time. If real GNP growth proceeds at a 6.0 percent rate after the end of 1971, unemployment is projected to average 5.8 percent for all of 1972 and 5.3 percent for 1973. On this expansion path, the unemployment rate would reach about 5.5 percent by the end of 1972 . If expansion proceeds at a 7.0 percent rate starting in 1972, unemployment is predicted to average 5.7 percent in that year and 4.8 percent in 1973. By these estimates, a rapid rate of expansion will have to be sustained for several years in order to restore full employment.

\section{A P P ENDIX}

\section{Labor Force and Employment Data}

\section{Definition and Census Changes}

The labor force concepts used in this study cover all persons aged 16 and over, including those in the armed forces. Some adjustments have been made to the official data. First, the official population, labor force, and employment data from the Current Population Reports (CPR), subdivided by age-sex groups, were adjusted for the $1950^{1}$ and $1960^{2}$ census population benchmark changes. The data were assumed correct in the most recent census (for example, 1960). The estimates for 1960 based on the 1950 census measured the error in the 1950 census for 1960; and years between census dates were adjusted on the assumption that the error grew linearly between census years. Second, the data for the labor force and employment were ad-

1. See U.S. Bureau of the Census, Current Population Reports, Series P-57, No. 129 (1953), pp. 5, 12.

2. See Employment and Earnings, Vol. 8 (April 1962), p. xvii. 
justed for the definition changes introduced by the Bureau of Labor Statistics in 1967. The overlapping data for 1966 provided by the Bureau of Labor Statistics were used to make the adjustment. ${ }^{3}$ These data provide estimates of employment and the labor force on both the old and new definitions. The ratio of the two estimates in the overlap period was applied to data for previous years to put all series on the basis of present definitions.

\section{Linkage to Establishment Data}

Employment totals from the Office of Business Economics, based on establishment reports and expanded to cover sectors excluded by those reports, ${ }^{4}$ were used in the measure of labor input of this study. For each year, discrepancies between this employment total and the total derived from the adjusted data in the CPR series described above were allocated among secondary workers (all but males aged 25 to 64) according to the share of employment of each age-sex group in total employment of secondary workers. The same discrepancy was allocated to the labor force in each group. ${ }^{5}$ In this way, labor force and employment subtotals for each age-sex group were derived, adding up to the "establishment-Denison basis" totals used here.

Table A-1 compares series on the total labor force and unemployment rate based on these adjustments with the official series. The unemployment rates differ primarily because the armed forces are not included in the official series. The adjustments described above have only a slight effect on unemployment rates.

3. Employment and Earnings, Vol. 13 (February 1967), pp. 3-30.

4. The expanded totals were kindly provided by Edward F. Denison from a draft manuscript of a forthcoming study. The establishment data appear in U.S. Office of Business Economics, The National Income and Product Accounts of the United States, 1929-1965: Statistical Tables (1966), Tables 6.3, 6.4, and 6.6, and in Survey of Current Business, July issues, Tables 6.3, 6.4, and 6.6.

5. This procedure amounts to assuming that the discrepancy is a reporting error in the employment estimates of secondary workers in the CPR series. Alternatively, it could have been assumed to arise from variations in multiple job holding, resulting in a somewhat different allocation of the discrepancy among age-sex groups. Since either secondary workers or second jobs would receive low weights in converting to the labor input measure used in this study, and since both would be cyclically sensitive totals, it makes little difference for the end result which adjustment is made. The evidence that the discrepancy was due to systematically variable multiple job holding was not persuasive. 
Table A-1. Derived Labor Force and Unemployment Rates Compared with Official Data, 1948-70

Labor force data in thousands

\begin{tabular}{cccccc}
\hline & \multicolumn{2}{c}{ Labor force } & & \multicolumn{2}{c}{ Unemployment rate } \\
\cline { 2 - 3 } \cline { 5 - 6 } Year & Derived & Official & & Derived & Official \\
\hline 1948 & 61,737 & 62,080 & & $3.5 \%$ & $3.8 \%$ \\
1949 & 61,816 & 62,903 & & 5.7 & 5.9 \\
1950 & 63,125 & 63,858 & & 5.1 & 5.3 \\
1951 & 65,756 & 65,117 & & 3.0 & 3.3 \\
1952 & 66,879 & 65,730 & & 2.7 & 3.0 \\
1953 & 67,691 & 66,560 & & 2.6 & 2.9 \\
1954 & 67,653 & 66,993 & & 5.1 & 5.5 \\
1955 & 68,453 & 68,072 & & 4.0 & 4.4 \\
1956 & 69,867 & 69,409 & & 3.8 & 4.1 \\
1957 & 69,923 & 69,729 & & 4.0 & 4.3 \\
1958 & 69,957 & 70,275 & & 6.4 & 6.8 \\
1959 & 70,474 & 70,921 & & 5.2 & 5.5 \\
1960 & 71,555 & 72,142 & & 5.2 & 5.5 \\
1961 & 72,236 & 73,031 & & 6.4 & 6.7 \\
1962 & 72,889 & 73,442 & & 5.2 & 5.5 \\
1963 & 73,872 & 74,571 & & 5.4 & 5.7 \\
1964 & 75,010 & 75,830 & & 4.9 & 5.2 \\
1965 & 76,789 & 77,178 & 4.3 & 4.5 \\
1966 & 79,529 & 78,893 & 3.5 & 3.8 \\
1967 & 81,216 & 80,793 & 3.7 & 3.8 \\
1968 & 83,019 & 82,272 & 3.4 & 3.6 \\
1969 & 85,126 & 84,239 & & 3.3 & 3.5 \\
1970 & 86,253 & 85,903 & & 4.7 & 4.9 \\
\hline
\end{tabular}

Sources: Derived data are discussed in the text of this appendix. The official data are from Manpower Report of the President, April 1971, pp. 203, 223.

\section{Potential Labor Force and Employment}

Table A-2 shows the participation rate equations used to estimate the potential labor force. In order to project potential employment disaggregated by age-sex groups, an assumption was needed about how individual group unemployment rates would be distributed at potential. Experience suggests that proportional changes for all groups would understate the change for groups with high unemployment, while the same percentage point change for all would overstate it. I chose an adjustment lying between 
Table A-2. Coefficients for Labor Force Participation Rate Equations

\begin{tabular}{lcccccc}
\hline \multicolumn{1}{c}{$\begin{array}{c}\text { Age-sex } \\
\text { group }\end{array}$} & Constant & $\begin{array}{c}\text { Labor } \\
\text { market } \\
\text { tightness } \\
1-u^{*}\end{array}$ & $\begin{array}{c}\text { Time } \\
\text { trend } \\
\text { log } T\end{array}$ & $\bar{R}^{2}$ & $\begin{array}{c}\text { Standard } \\
\text { error } \\
\text { of } \\
\text { estimate }\end{array}$ & $\begin{array}{c}\text { Serial } \\
\text { correla- } \\
\text { tion co- } \\
\text { efficient }\end{array}$ \\
\hline Males & & & & & & \\
16-19 years & 0.0695 & 1.2961 & -0.3268 & 0.910 & 0.0126 & 0.775 \\
20-24 years & $(0.3243)$ & $(0.2676)$ & $(0.0950)$ & & & \\
25-64 years & -0.3548 & 0.9373 & 0.1524 & 0.781 & 0.0157 & 0.903 \\
65 years and & $(0.4787)$ & $(0.3183)$ & $(0.1740)$ & & & \\
over & 1.0232 & 0.0106 & -0.0405 & 0.805 & 0.0024 & 0.872 \\
Females & $(0.0684)$ & $(0.0488)$ & $(0.0237)$ & & & \\
16-19 years & 1.4900 & 0.4393 & -0.7254 & 0.985 & 0.0089 & 0.860 \\
20-24 years & -0.5172 & $(0.1839)$ & $(0.0855)$ & & & \\
25-64 years & $(0.3296)$ & $(0.3128)$ & $(0.0670)$ & & & \\
& -0.7945 & 0.4991 & 0.3781 & 0.881 & 0.0120 & 0.866 \\
65 years and & $(0.3420)$ & $(0.2466)$ & $(0.1172)$ & & & \\
over & -1.2908 & 0.4780 & 0.5750 & 0.987 & 0.0055 & 0.759 \\
\hline
\end{tabular}

Source: Based on official labor force data, adjusted as described in the text of this appendix. The dependent variable is the fraction of the population in each group that is in the labor force. The form of the equations and the results are discussed in the section, "Participation Rates," in the article text. All regressions were fitted to annual data for 1947 to 1969 . The standard errors of coefficient estimates are in parentheses.

these extremes: For each age-sex group in each year, I calculated the "total unemployment rate," defined as the sum of recorded unemployment plus hidden unemployment (the difference between the trend and actual labor force for the group) as a ratio to its trend labor force. At a point in time, this total unemployment rate was assumed to change proportionately for all age-sex groups. The size of the proportionate change in each year was calculated by constraining the total weighted unemployment rate to be 3.37 percent, its constant value along the trend path. Then the same proportional changes in employment were maintained in shifting from the trend to the potential path. Since the groups that experience relatively high unemployment rates also experience large changes in labor force participation as unemployment varies, this way of adjusting individual rates to their po- 
tential levels falls between the extreme methods of adjustment mentioned above.

Potential employment in each age-sex group for each year was multiplied by the relative wage of workers in that group. These wage-weighted employment estimates for each group were added together to get weighted potential employment for the whole economy. Actual weighted employment was estimated in a parallel manner by adding actual wage-weighted employment over all age-sex groups. 


\section{Comments and Discussion}

Edward F. Denison: I am a little embarrassed because to discuss Perry's paper I must discuss my own recent research. It consists of another growth study of the general type I have made before, with numerous improvements and refinements. It provides annual estimates for the United States covering the postwar period, 1947-69, and a few prewar years on a comparable basis.

In any such study, the first prerequisite is to obtain output and input measures that are as statistically consistent as possible. It is a great advantage that the Office of Business Economics (OBE) series on compensation of employees is matched by an employment series based on the same sources and processed in the same way. OBE's estimates of proprietors are also a series as consistent with proprietors' income as one can obtain. To maximize consistency between input and output, I measured output from the income side of the accounts (if one starts from the expenditure side the deflated statistical discrepancy is subtracted) and used OBE employment data as the main basis for an employment series. Conceptually, the series is on a labor force basis, to permit a tie-in with labor force characteristics obtained from the Current Population Survey (CPS), but the movement is based essentially on the OBE employment data. While my employment series differs from the CPS employment series, the differences are not in long-term trends, nor in cyclical movement to any great extent. The main difference is that there are periodic changes in their relative levels: One is above the other for a number of years, then they cross over for another series of years, again reverse, and so on. 
Hours are based on establishment data from the Bureau of Labor Statistics (BLS), related to this employment series. A small adjustment, based on unpublished BLS estimates, converts hours paid for to hours worked. So much for background.

Perry has picked up my employment and hours series for his analysis. He obviously must use an "actual" labor force series that is statistically consistent with employment, and has obtained it by adding to employment an estimate of unemployment. I am convinced that, besides having the merit of consistency with output, this is a better time series for the labor force than the CPS series. Perry also required a consistent series for the potential labor force. To obtain it he needed an age-sex distribution of the actual labor force, which he derived by scattering the difference between the actual labor force as estimated and the CPS series among the groups whose labor force participation rates fluctuate.

One result of Perry's analysis particularly interested me: When the new labor force series is used, a cyclical response of the labor force to the unemployment rate remains. Until he conducted his analysis I had no idea whether this response would appear. I completely agree with Perry's procedure of measuring the potential labor force by starting from the actual and adding or subtracting the gap or surplus.

Perry's next problem was to obtain a cyclically adjusted average hours series. His rather arbitrary solution was to break the period into three pieces and use a trend value for each. He might do a little better up to 1965 by looking at employment components. Until then the main changes in average hours resulted from compositional shifts in employment from farm to nonfarm, from men to women, from full-time to part-time work, and so on. However, the big drop after 1965 was not compositional alone; hours dropped within homogeneous groups. I have no real criticism of Perry's procedure. Any way one handles the recent period will be arbitrary.

The projection assumes the old rate of decline in hours starting from the new lower level. Because changes in hours are likely to be discrete rather than gradual, they are essentially nonprojectable over periods of five or ten years or less. Nevertheless, given the assignment, I should probably have made the same assumption.

The rest of the study involves attempts to measure a trend rate of productivity change and cyclical fluctuations in productivity. I would not say Perry's results are necessarily wrong, but I must raise some questions. The broadest point is simply this: Output per weighted manhour in the whole 
economy, his measure of productivity, is so summary a measure that it is hard to analyze it, draw any conclusions, or appraise the results.

Perry and I agree in some sense on one statement: There has been no important acceleration or deceleration in the rate of productivity increase during the postwar period. If there has been any change, it was small. The trouble is that we define productivity in such different ways that if one of us is right, the other is in all probability wrong. Also, when I consider the three periods Perry distinguishes, I obtain a lower rate of change in the middle period than in the other two, while he does not.

Both series attempt to eliminate cyclical movements, but otherwise they are quite different. Perry defines productivity as GNP per hour worked, weighted by age and sex, in the economy as a whole. The series in which I find stability is confined to the nonresidential business sector of the economy, and within this sector measures output per unit of total input after the effects of shifts of resources out of labor and out of nonfarm selfemployment, of cyclical movements, and of minor sources of irregularity are eliminated.

My first point concerns the size of the sector covered: Unless by chance all sectors march side by side, trouble arises in dealing only with the economy as a whole. The government-household-institution sector is measured differently, behaves differently, and affects all numbers differently from the business part of the economy. Output per manhour in that sector has increased about one-third of a percent per year, much lower than the rate in the nonresidential business sector, and its share in the total has shifted up and down. Aside from the difference in the rate of productivity change, shifts in the importance of the sectors themselves affect their combined output per manhour.

In a large part of the economy, consisting of the services of dwellings plus income from abroad, output is produced with almost no manhours at all; it is entirely a product of capital. Output of these sectors should be eliminated to analyze output per manhour, and added back to obtain output in the entire economy. A rise in the proportion of output in these sectors raises output per manhour in the whole economy; a decline reduces it. The proportions have changed rather substantially over this period and not at a constant rate.

A broader point concerns what one is trying to do in this type of analysis. I start with the proposition that changes in manhours are only one of many determinants of output. One should go on to take separate account of all 
the determinants that affect output, or output per manhour, that can be identified and measured annually. What is left is a residual whose growth one seeks to analyze for trend.

Perry has taken account of one such determinant, the age-sex composition of hours worked. He says that other determinants, such as education or capital, are also important but that they generally change smoothly and can be allowed to ride in the residual productivitity trend.

I have tried to measure directly the effects of a much larger number of determinants. Table 1 presents some comparisons between Perry's results and mine. His numbers, however, refer to the whole economy, mine to the nonresidential business sector, which represents about four-fifths of total national income, on the average; Perry refers to potential hours, while I deal with hours actually worked.

Line 1 shows growth rates of Perry's labor input per man, which changes only because of age-sex composition. Below it are three of my series. These are total labor input per person employed; total input per person employed; and total input per person employed plus the effects of shifts out of agriculture and self-employment.

\section{Table 1. Comparison of Perry and Denison Measures of Annual Growth Rates of Input per Man and per Manhour, 1948-70}

Percent

\begin{tabular}{lrrrrr}
\hline \multicolumn{1}{c}{ Type of measure } & $1948-55$ & $\begin{array}{c}\text { Change } \\
\text { to next } \\
\text { period }\end{array}$ & $1955-65$ & $\begin{array}{c}\text { Change } \\
\text { to next } \\
\text { period }\end{array}$ & $1965-70^{\mathrm{b}}$ \\
\hline Input per man & & & & & \\
$\begin{array}{l}\text { 1. Labor input, Perryc } \\
\text { 2. Labor input, Denison }\end{array}$ & -0.62 & 0.01 & -0.61 & -0.57 & -1.18 \\
$\begin{array}{l}\text { 3. Total input, Denison } \\
\text { 4. Total input plus resource }\end{array}$ & 0.51 & -0.36 & 0.15 & -0.43 & -0.28 \\
$\quad$ reallocation, Denison & 1.24 & -0.40 & 0.46 & -0.39 & 0.07 \\
$\begin{array}{l}\text { Input per manhour } \\
\begin{array}{l}\text { 5. Labor input, Perryc } \\
\text { 6. Labor input, Denison }\end{array}\end{array}$ & -0.11 & -0.14 & -0.25 & -0.28 & -0.53 \\
7. Total input plus resource & 0.08 & -0.29 & -0.21 & -0.20 & -0.41 \\
$\quad$ reallocation, Denison & 1.66 & -0.51 & 1.15 & 0.18 & 1.33 \\
\hline
\end{tabular}

Source: See text.

a. The Perry measures concern the potential for the whole economy and potential hours; the Denison measures, the actual for the business sector only and actual hours worked.

b. Perry: 1965-70; Denison: 1965-69.

c. Takes account of age-sex composition only. 
Line 7 can be viewed as my estimate of the effects on output per manhour in the nonresidential business sector of all the factors that can be identified and measured annually, of which age-sex composition is only one. Now, the levels do not affect Perry's analysis; what matters is the change from one time span to the next (the second and fourth columns).

It turns out that changes in the growth rate of Perry's labor input per manhour are not at all similar to changes in the growth rates of the sum of all my separately identified factors per manhour shown in line 7.

While my calculations have yet to be completed, I suggest that the agesex calculation, although appropriate as far as it goes, may give a diametrically erroneous indication of the effects on output per manhour of all identifiable and measurable factors in total input and resource shifts.

My last general point concerns the method of adjusting the data to untangle trend and cyclical movements. Table 2 is designed to show how different our numbers are in Perry's first period.

I first set down our growth rates of actual output per manhour in the whole economy, whose differences lie only in the measure of output. Although Perry measures output by GNP and I by national income, the difference between our estimates, shown in lines 1 and 3 , is not due mainly to the difference in definition. Inclusion of line 2 brings out the fact that most

Table 2. Comparison of Perry and Denison Measures of Annual Growth Rates of Economy-wide Output per Manhour, 1948-70

Percent

\begin{tabular}{lrccc}
\hline \multicolumn{1}{c}{ Type of measure } & $1948-55$ & $1955-65$ & $1965-69$ & $1965-70$ \\
\hline $\begin{array}{l}\text { Actual output per manhour } \\
\text { 1. GNP (product side), Perry }\end{array}$ & 3.45 & 2.75 & $\ldots$ & 1.63 \\
$\begin{array}{l}\text { 2. GNP (income side), Denison } \\
\text { 3. GNP, national income accounts basis } \\
\quad \text { (income side), Denison }\end{array}$ & 3.27 & 2.85 & $\ldots$ & 1.64 \\
$\begin{array}{l}\text { Potential output per manhour } \\
\text { 4. GNP (product side), Perry }\end{array}$ & 2.87 & 2.71 & $\ldots$ & 2.39 \\
$\begin{array}{l}\text { 5. GNP, national income accounts basis } \\
\quad \text { (income side), Denison }\end{array}$ & 3.31 & 2.66 & 2.81 & $\ldots$ \\
$\begin{array}{l}\text { Actual less potential } \\
\text { 6. Perry (line 1 minus line 4) }\end{array}$ & & & & $\ldots$ \\
7. Denison (line 3 minus line 5) & -0.12 & 0.22 & -1.02 & $\ldots$ \\
\hline
\end{tabular}

Source: See text. 
of the difference results from my measuring output from the income side while he measures it from the product side. It happens that for these particular periods, especially for a comparison of $1948-55$ with $1955-65$, the choice makes a big difference.

Line 4 shows the growth rate of Perry's potential output per manhour and, for a rough comparison, line 5 gives a series constructed from my estimates. I adjusted actual output in the nonresidential business sector each year to what it would have been if the labor and capital present had been used at a constant rate of utilization, added this to actual output in the other sectors, and divided by actual total hours in the whole economy.

The point of the table is to be able to compare lines 6 and 7, obtained by subtracting the growth rates of potential from those of actual output per manhour to obtain the effect of the cyclical adjustment.

Our numbers are, perhaps, not very far apart for the later periods. But they are very different for the first period. I estimate that 1948 saw a moderately more intense use of resources than 1955 . Perry's growth rate of 0.58 over seven years implies that output per manhour in 1955 was roughly 4 percent higher than it would have been with the 1948 utilization rate.

To be sure, lines 7 and 6 are not estimates of precisely the same thing. Line 7 estimates what output per manhour of the hours actually worked in each year would have been if they were not affected by changes in utilization, whereas line 6 provides a measure of what the output of all the potential hours would have been. Still, I don't think very big differences in the numbers can be explained this way.

In seeking a means to adjust productivity for changes in intensity of utilization, it seemed to me that the series most likely to be affected by such changes in the same way and at the same time as productivity was profits, or more precisely, the nonlabor share of corporate national income when depreciation is measured in current prices and on a consistent basis. I used this series to estimate the fluctuation in productivity. My approach was to compute a logarithmic trend for the most refined series on output per unit of input I could obtain, and compute an arithmetic trend (which is slightly downward) for the nonlabor share. Deviations of productivity and the nonlabor share from their trends were correlated, and the regression was used to estimate from the nonlabor share the effects of intensity of utilization on productivity each year. The correlation is pretty good; $\bar{R}^{2}$ is 0.90 . I also superimposed another adjustment to eliminate the effect of irregular movements in the relationship between wages and prices on 
the nonlabor share itself. This refinement changed some of the numbers a little, but not very basically.

What were the alternatives? In his initial study, the portion of Okun's law reflecting the adjustment for productivity was obtained by a relationship to unemployment, as were the rest of its components. In Why Growth Rates Differ, I picked up the productivity part of Okun's formula, although I was unhappy with it. In the process of my current study, with the advantage of more years of data, I tested it and there was no correlation at all between productivity and unemployment; the calculation comes out literally as close to zero as one ever gets.

Another possibility was the change in hours worked from one year to the next, which performed better than unemployment but still not very well, giving improbable answers in some years. Then I tried both unemployment and the change in hours, and this worked no better than the change in hours alone. There are good reasons why the change in hours should not be a satisfactory indicator. For example, labor hoarding reduces productivity but raises hours worked so the causation is often backward.

In his analysis here, Perry first uses the unemployment rate. I suspect this does nothing for him at all. I checked directly on the relationship between output per manhour for the whole economy and the unemployment rate. The correlation is for all intents and purposes zero, and only trivially better if his weighted unemployment rate is used. True, I used national income as an output measure but this shouldn't matter unless the statistical discrepancy and unemployment are highly correlated. Perry also introduces a measure of the change in hours not worked. This helps quite a bit, but only about as much as the change in hours in my analysis. The two measures are close substitutes and either is helpful only in periods of rapid expansion. I doubt that Perry has as good a measure of utilization as one can get. In many years his method will yield estimates close to those obtained by my procedure but in occasional years-particularly those like 1953 or 1957 that embrace the beginning of a downturn - it yields a very different, and I believe worse, answer. The 1948-55 movement revealed in Table 2 suggests his results are quite different from mine, but I have not seen estimates for all the other years.

I do not want at this point to say that any of Perry's conclusions or his projection is wrong, yet I am reluctant to accept them as right. The whole operation is insufficiently detailed to permit much evaluation, and the procedure for cyclical adjustment of productivity is not very good. 
As a final comment about the very recent period, I think it interesting that, after allowing for variation in intensity of utilization, neither of us finds any drop in the rate of productivity increase-in my case through 1969 and in Perry's through 1970. The differences in measuring inputs discussed above are probably not very important in this short-term examination of very recent changes.

Robert M. Solow: When Perry first introduced the weighted employment concept in his inflation paper last year, I felt an impulse to suspend judgment about it because I was worried about whether it was a concept that simply happened to meet the requirements of the moment and might not last. Now I think that the success with which the weighted employment concept comes out here also lends, in my mind, more credibility to the analysis in the inflation paper as well. Not that there is any logical connection between the two, but the concept seems to me to be paying off.

Next, I agree with Perry that there is no evidence whatever in his paper for moving away from the hypothesis of a constant weighted productivity trend in the period. Only one equation in his Table 2 yields any worthwhile difference, and I mean worthwhile rather than statistically significant. Some differences shown in the table are not worthwhile in the sense that they are trivial and well within the specification error of any model of this kind. Equation (11f), the one equation that does yield a worthwhile difference, is suspicious on other grounds.

Finally, when it comes to accounting for the relatively slow growth of his measured potential between 1965 and 1970, Perry puts a quarter of 1 percentage point of the rate of growth on the unusually fast reduction of average hours. In the model, this comes from the dummy variable for 1966-68 which, as Perry says perfectly clearly in the paper, is strictly ad hoc. In a sense it is still unexplained. It is just that the data seemed to call for this kind of unusual reduction in hours during that period. There is probably something to it, although I do not understand why it happens. It helps explain another mystery-the decline (or, at best, the failure to rise) of real spendable weekly earnings of production workers between 1965 and 1970, even while real hourly compensation has been rising. Presumably, a good chunk of the reason lies in the autonomous reduction in hours for which we have no special explanation.

One question I have is why Perry's potential output grows faster than what he calls official potential output between 1965 and 1970. I was puzzled 
too, as Denison was, but in obviously quite a different way, about the 1948-55 comparisons because Perry's productivity figures imply a gapclosing productivity gain in that interval, yet the official unemployment rate was lower in 1948 than in 1955.

The discrepancy between Perry's and Denison's numbers that I would like cleared up is that Perry's series for the rate of growth of output per unit of his labor input looks constant on his potential path; and Denison's series for the rate of growth of output per unit of total input is, he says, constant along his potential path. The difference between these is the rate of growth of Perry's labor input per unit of Denison's total input. The difference between two constants should be constant. But Denison says this difference is not.

To finish up, I have two very brief comments on some of the material relating to the Okun multiplier. Perry points out that he can formulate this model in different ways, essentially interchanging dependent and independent variables, and get slightly different results for the Okun multiplier. If either weighted hours or output were treated as exogenous in the model, it ought to be the independent variable. In the present case, I presume one would take output as the independent variable on the assumption that the causality runs from output to hours, with output in turn given by product demand. But it would be better still to imbed this analysis in a somewhat more complete model of the economy in which some variables were clearly exogenous, and then estimate the complete system.

George L. Perry: Let me first try to respond to the array of results and observations Denison has offered. On the question of what output concept to use, I went directly to total GNP because that was what I was interested in. Measuring it from the input side is one alternative. I doubt that it makes a difference in analyzing potential since the two concepts differ only by the statistical discrepancy, although it can make a noticeable difference in measuring actual output or productivity changes between two years. I accept Denison's comment that a productivity analysis is cleaner if it excludes some parts of GNP, particularly those for which we measure or impute output that involves no labor input. But sectoral shifts are a part of all observed changes and are important even within the nonfarm business sector. Weighting labor input, as I have done, takes account of shifts from the input rather than the output side. If the growth of an imputed part of output, such as household services, changed sharply over the 
period, it could still affect the results. I have treated such changes as gradual in dealing with total GNP and in allowing their effects to appear in the trend term.

The Perry and Denison concepts that are displayed side by side in Denison's Table 1 are so different that they are hard to compare. Denison uses actual data for part of the economy and compares them with my data on potential for the economy as a whole. Where we are closest to measuring the same thing, labor input per manhour, the big disparities in our changes between the first and second periods are worth noting. These probably reflect the large residuals that exist in the first few years in my analysis. Then, productivity moved erratically, even after adjustment for cyclical variations in unemployment. Thus, growth rates such as his, using actual data over a few years, will vary sharply according to which of the early years one starts with. Growth rates along my potential line will not.

The differences between Denison's series on labor input and his series on total input plus resource allocation indicate that everything but labor input grew unevenly when measured per hour of labor input. If some of these other factors are treated as fixed inputs, some uneven movement would be accounted for by the fact that manhours vary cyclically along the actual path. In any case, without a careful study of Denison's work it is hard to know what to make of this as a comment on my results.

The nearest that we can come to comparing our work is in the data on potential growth rates given in Table 2 . Here our results on economy-wide productivity trends are summarized using conventional manhours in both cases. Yet the comparison is still elusive, because of two essential differences.

First, what Denison calls potential is not what I call potential; the two are defined differently. His potential is defined by making the nonlabor share a prescribed fraction of total income-almost, but not quite, a constant fraction through the years. My potential is defined by holding the unployment rate at a fixed level each year.

Second, I am purposely measuring along a smoothed trend line. Denison is measuring from the end points of a potential path calculated by adjusting actual productivity in each year for his estimate of underutilization each year (defined by the ratio of the actual nonlabor share to his trend value for this share).

Our most substantial and important disagreements center on the last period. If I adjust his potential growth rate for the difference between out- 
put measured from the product and the income sides, our differences in the first two periods are rather small despite all the differences in concept and definition. But for the crucial last five years, our disagreements matter for we say significantly different things about what has happened recently to productivity and where the economy would be if it were at "potential." Here I find Denison's results implausible if he means them to apply to something near my concept of potential. In this period, the trend in productivity per manhour in my analysis slows by 0.32 percentage point from the earlier period. In Denison's figures, the trend quickens by 0.15 percentage point. My numbers imply a constant productivity trend on my labor input basis, which produces the decline in the trend on an unweighted manhour basis since so many women and young workers entered the work force over this interval. If instead I accept Denison's numbers for unweighted manhour productivity, and take them to apply to what I mean by potential, the productivity trend on my labor input basis jumps by 0.47 percentage point in this period rather than remaining constant. I find a productivity revolution of this size implausible on the face of it and inconsistent with all the statistical evidence in my paper. While I am only speculating, I suspect Denison's 1969 end point is the main source of our difference. The nonlabor share was at recession levels that year. I suspect that low profits were an even bigger surprise than low productivity - that is, the unexplained residual in profits was greater. And if this is so, Denison adjusted productivity up by more than he should have.

The answer to the first of Solow's questions-Why is the 1948 to 1955 actual productivity gain larger than the gain on the potential path?-has to do again with the residuals for the earliest years, which reflect erratic movements of measured productivity and make actual end-point calculations misleading. With my data, 1948 shows a positive output gap measured using the trend line, despite a very low unemployment rate; 1950 shows a much smaller output gap despite an unemployment rate that is 1.6 percentage points higher. Actual productivity growth from 1948 to 1955 averages more than trend even though, without residuals, we could expect growth slower than trend because of some gap opening between those years. Actual productivity growth from 1950 to 1955 averages the same as trend even though, without residuals, we would expect growth to be faster than trend because of gap closing between those years. One should not take such calculations from these early years too seriously.

Solow also asks about the comparison of my estimates with the official 
estimates of potential output growth. The official series grows more slowly because, as near as I can tell, it is not measured accurately. The ingredients of the official estimate are unclear. I think that, as the growth in the labor force surprised the Council of Economic Advisers each year, they moved the potential path up a little bit. They did not make the full leap at any one time because to retain the rest of the trend calculation - the average hours and productivity trends-while accepting the evidence on the acceleration of the growth in the labor force would have moved potential up very rapidly, as I have indicated. The surprising thing is that they came out pretty close, by sheer luck perhaps, since the ingredients that would allow a calculation of the change in the productivity trend measured conventionally were never part of the analysis. The unemployment rate and Okun's law surely kept them compromising on how fast to move up the potential path and kept them in the ball park. Basically it was telling them that something was holding down potential output growth despite the acceleration in the labor force.

Finally, there is the question of which productivity trend has really been "constant." I make no claims beyond those discussed in the paper for the constancy of productivity trend on the basis of my input measure. Statistical tests designed to find significant changes could not shake the hypothesis that the trend was constant throughout the period (although what insignificant evidence there was indicated a slowdown in recent years, while Denison implies an acceleration). I have seen no statistical evidence of constancy on Denison's concept. Conceivably, we could both be right since he does not mean by potential the same thing that I mean. But without seeing a great deal more of his analysis, including how he measures the contribution to potential output of capital, education, and other things, I cannot say whether I would accept this coincidental result. If I may borrow his phrase, I would not say Denison's results are necessarily wrong, but I must raise some questions.

\section{General Discussion}

Arthur Okun noted that Perry's results on the Okun's law multiplier were not surprisingly different from his own. He noted that his original work had shown differences in the multiplier similar to those shown by Perry, according to which question was asked. His original regressions, 
which sought to estimate the unemployment rate if output grew 1 percent faster than potential, gave a multiplier of around 3.2; asking what output gain accompanied a one-point reduction in the unemployment rate gave a multiplier of around 2.5. The difference comes because the correlations are not perfect, and they are similar to Perry's differences. He also had suspected that if lags were allowed explicitly, as in Perry's equation (11) in contrast with (7), some of what is attributed to the level of the gap would turn out to result from changing the gap. This helps account for the lower level of both of Perry's multipliers compared with Okun's original estimates.

R. J. Gordon suggested that it would be useful to try to introduce the possible influence of wage and price expectations into the labor force participation equations to see if they helped explain the unusual rise in participation rates of recent years. This calculation would help decide if the high participation rates were permanent or transitory. He also suggested, as a possible explanation of the drop in hours in 1966-67, that tight labor markets may have induced an unusual number of women who ordinarily would not work at all to take up part-time jobs in retail trade and services, and that this effect would vanish when employers could hire full-time personnel in a slacker labor market. He believed this may have been happening in 1971. 